\title{
Anti-gp100 TCR Retroviral Vector- Transduced Autologous TIL
}

National Cancer Institute

\section{Source}

National Cancer Institute. Anti-gp100 TCR Retroviral Vector-Transduced Autologous TIL. NCI Thesaurus. Code C38135.

Human tumor infiltrating lymphocytes (TIL) isolated from a melanoma patient and were eng ineered to react with the melanoma antigen glycoprotein 100 (gp100). These TIL are transfected with a retroviral pGCsam vector encoding T-cell receptors specific for gp100, grown in culture, and then transferred back to the patient. These genetically modified TIL may recognize and halt the growth of gp100-expressing melanoma cells. 